\title{
Limb-Girdle Muscular Dystrophy
}

National Cancer Institute

\section{Source}

National Cancer Institute. Limb-Girdle Muscular Dystrophy. NCI Thesaurus. Code C84828.

A group of autosomal recessive and less frequently autosomal dominant muscular dystrophies affecting the muscles of the hips and shoulders. 